\title{
Task-Relationship-Self:
}

\section{A Framework for Understanding Service Encounter Behaviors}

\author{
Graham L. Bradley \\ Griffith University, Australia \\ Phone: +617 5552 8743. Email: g.bradley@griffith.edu.au \\ Beverley A. Sparks \\ Griffith University, Australia \\ Phone: +617 5552 8766. Email: b.sparks@griffith.edu.au \\ Dieter Zapf \\ Goethe University, Germany \\ Phone: +49069 9798 23786. Email: d.zapf@psych.uni-frankfurt.de \\ Janet R. McColl-Kennedy \\ UQ Business School \\ The University of Queensland, Australia \\ Phone: +617 3346 8178. Email: j.mccoll-kennedy@ business.uq.edu.au \\ Nerina L. Jimmieson \\ The University of Queensland, Australia \\ Phone: +617 3365 6409. Email: nerina@ psy.uq.edu.au
}

Corresponding Author:

Associate Professor Graham Bradley

School of Applied Psychology and Behavioural Bases of Health Research Centre, Griffith Health Institute, Griffith University, Queensland, 4222. Australia.

Phone: +617 5552 8743. Fax: +617 5552 8291. Email: g.bradley@griffith.edu.au

Acknowledgement:

This research was supported under Australian Research Council's Discovery Projects funding scheme (project number DP0879469). 


\title{
Task-Relationship-Self:
}

\section{A Framework for Understanding Service Encounter Behaviors}

\begin{abstract}
Research conducted over past decades has investigated selected service encounter behaviors from either a customer or service provider perspective. However, a comprehensive, dualperspective framework is lacking. Such a framework is needed to organize knowledge of these behaviors, and thereby provide structure, clarity, and parsimony to the field. This paper describes a three-tier framework of service encounter behavior that was developed by applying grounded theory principles to interviews with customers, service employees, and other stakeholders. These informants described many ways in which they behave when executing service exchanges, dealing with service difficulties, and managing themselves in the process. Using an iterative inductive approach, a conceptual framework was developed in which specific (Tier 1) behaviors were placed within broader (Tier 2) categories, and these lower classification levels were, in turn, interpreted within a conceptual space defined by the (Tier 3) dimensions of task, relationship, and self. This framework was then elaborated and refined by reference to the psychology and marketing literature, a set of 157 audio-recorded service interactions, and an expert panel study. The paper includes comparisons between the framework and those previously proposed, propositions regarding service encounter processes and outcomes, and implications for future research and practice.
\end{abstract}

KEYWORDS: service encounters; service interaction behaviors; socio-emotional behaviors; service employees; communication. 


\section{Task-Relationship-Self:}

\section{A Framework for Understanding Service Encounter Behaviors}

Across the globe every day customers and employees engage in millions of service interactions. Poorly transacted interactions incur significant costs, including customer dissatisfaction, disloyalty, rage and revenge, as well as employee stress-related illness, absenteeism and turnover, and losses to organizational productivity and profits (DrachZahavy, 2010; Gregoire \& Fisher, 2008; McColl-Kennedy, Patterson, Smith, \& Brady, 2009). Identifying ways to improve service interactions is critical to both employee and customer well-being, and is identified as an important research goal for the current decade (Ostrom, Bitner, Brown, Bunkhard, Goul, Smith-Daniels, et al., 2010).

Much of the past research into service encounters has involved obtaining satisfaction, loyalty and similar data from one party only (usually the customer), and drawing inferences regarding service quality, service improvement, and, possibly, organizational strategic direction, from this one-sided perspective (Svensson, 2006). However, service encounters involve at least two parties (Côte, 2003; Brown \& Lam 2008; Rafaeli, 1989). Just as customer satisfaction and repatronage (and ultimately organizational performance) depend on employee service encounter behavior, employee behavior, in turn, depends on customer actions (Heskett, Sasser, \& Schlesinger, 1997; Homburg \& Stock, 2005; Loveman, 1998). Consistent with this dual perspective, the current paper reports an investigation of the behaviors displayed by both parties involved in service interactions. The aim was to identify and classify these behaviors, and thereby build a conceptual framework that can be used in future research and interventions to improve service encounter outcomes.

The remainder of this paper is organized as follows. First, the conceptual background is reviewed briefly. Second, details are given of an interview-based study and of the modified 
grounded theory approach applied to this study to develop the Task-Relationship-Self (T-RS) framework of service interaction behaviors. Third, the framework is extended, refined and corroborated using additional research. Fourth, relationships with prior marketing and psychology literature are examined. Fifth, applications are suggested, as are several research propositions. Finally, limitations are identified and conclusions drawn. Major contributions of this paper thus include the development of a framework for describing, understanding, and enhancing the effectiveness of behaviors within service interactions, as well as a platform and set of testable propositions to guide future research. As will be shown, the framework provides a useful way of synthesizing past work, incorporating both customer and employee perspectives, and demonstrating links to successful/dissatisfactory outcomes.

\section{Conceptual Background}

Research into service interactions dates back several decades. For example, Nyquist, Bitner, and Booms (1985) argued, "[w] hat is needed is the identification and naming of the variables involved in the service encounter" (p. 210). Since then, numerous studies have sought to discover critical components of service interactions. Research by Bitner and colleagues (Bitner, Booms, \& Mohr, 1994; Bitner, Booms, \& Tetrault, 1990) found that the determinants of customer and employee satisfaction and dissatisfaction include aspects of the other party (e.g., an uncooperative customer), the other party's behavior (e.g., abuse), and the broader service context (e.g., service unavailability). Others (e.g., Davidow, 2003; Gremler \& Gwinner, 2008; Harris \& Ogbonna, 2002; Rafaeli, 1989; Sparks \& McColl-Kennedy, 2001) have focused more narrowly on service encounter behaviors, usually as performed by only one party to the interaction. Among the many subsets of service interaction behaviors previously studied are rapport-building behaviors, non-verbal behaviors, service recovery behaviors, service sabotage behaviors, and coping behaviors. Employee behaviors have been studied more often than have customer behaviors, with few writers developing conceptual 
frameworks that encompass the actions of both parties. Table 1 provides details of some of these past attempts to systematize knowledge of service interaction behaviors. While each has contributed to understanding the dynamics of service encounters, an overarching framework is needed to integrate the various contributions, understand their interdependencies, and thereby provide clarity and structure to the field.

[Insert Table 1 about here]

The goal of the current research was to develop a comprehensive classificatory framework of the behaviors that occur during customer-employee interactions. In developing this framework, it was necessary to examine all types of service interactions, successful or otherwise, and to recognize that behaviors and their consequences are likely to vary between, for example, face-to-face and telephone interactions (Rafaeli, Ziklik, \& Doucet, 2008) and between different service segments (Goodwin \& Ross, 1992). Behaviors that were of interest included those used to introduce and close interactions, those aimed at service delivery and where needed service recovery, those representing responses to the service received or to the attempt at recovery, and those aimed at self-regulation and the management of service encounter-related stressors. Particular attention was paid to behaviors that act as triggers to conflict instigation, escalation, and resolution. Effects of service encounter behaviors on the actor him/herself ("actor effects") and on the other party within the interaction ("partnereffects") were considered.

This focus on the behaviors of both customers and employees is consistent with the central tenets of consumer culture theory and the service dominant logic notion of co-creation of value (e.g., Payne, Storbacka, \& Frow, 2008; Vargo \& Lusch, 2004). These perspectives recognize that value is co-created by all participants in a service exchange. Rather than being passive recipients of service, customers are to varying degrees involved in the process with the service provider(s) (McColl-Kennedy, Vargo, Dagger, Sweeney, \& van Kasteren, 2012). 
Accordingly, the research reported here examined service interactions from both parties' perspectives, and explored processes of reciprocal influence within and beyond these dyads.

\section{Interview Study}

\section{Participants}

The foundation study involved one-on-one interviews with customers $(\mathrm{n}=16)$, frontline employees $(\mathrm{n}=28)$, and a stakeholder group that included supervisors, managers, consultants and a professional mediator, all of whom work with customer contact employees $(n=16)$. Recruitment of participants occurred incrementally, as informed by ongoing data collection and emerging theory. Customers were selected from a range of demographic groups; employees and managers were sourced from multiple service industries including hospitality, utilities, banking, education, government, insurance, and retail. Ages ranged from 18 to 66 years. Females comprised $50 \%$ of the customer sample, $68 \%$ of employees, and $87 \%$ of the supervisor/manager sample. Front-line employees had between 1 and 35 years of service work experience $(\mathrm{M}=10.2$ years $)$.

\section{Aims and Method}

An extensive manual was developed and used to train interviewers to provide the conditions under which informants would feel comfortable to recall and honestly report their experiences.Interviews were semi-structured using questions adapted from past studies (e.g., Rafaeli, 1989; Weatherley \& Tansik, 1993). Questions probed interviewees' perceptions of (a) the dynamics of service encounters, (b) behaviors within service interactions that were annoying and enjoyable, and (c) behaviors that led to service success and failure. Both overt behaviors, and less observable affective, cognitive and non-verbal responses were of interest. Some questions requested accounts of specific incidents, for example:

Think about a recent, difficult service exchange. Tell me what led up to it. What did you do, and how did you feel during the interaction? What, specifically, did the other 
person do, or say, that made you feel this way? What words did they use? How exactly did they express these words?

Other questions probed interviewees' opinions of alternatives to the behaviors displayed: Is there anything you could have done differently that would have prevented, or at least contained, this problem? What about the other party - what could or should have they done differently?

Further questions sought abstract generalizations about service encounter behavior. For example:

Can you tell me about the kinds of things service staff [customers] do that help you enjoy service interactions? And what things do they do that really delight you? What things do service staff [customers] do that really annoy you? ... And what do they do that completely outrages you?

What shouldn't service staff [customers] do? Why shouldn't they do that? How do you manage difficult service interactions? How do you do that?

A multi-stage approach was followed, drawing on the principles of grounded theory (Corbin \& Strauss, 2008). First, an initial set interviews was conducted. Analysis and reflection on these first interviews led to reassessment of the interview protocol. Question wording was adapted in the light of this initial set, and selection of later interviewees was guided by information and ideas initially obtained. Application of these iterative processes aimed to elucidate constructs that had been identified, but poorly understood, in earlier interviews. As the interview process reached saturation earlier in relation to routine than in relation to non-routine service interactions, increasingly over time questions were directed towards behaviors within out-of-the-ordinary (especially difficult) interactions. Interviewing continued until theoretical saturation was achieved. Interviews lasted between 15 and 80 
minutes (although all but two were between 25 and 55 minutes; Mean $=39 ; S D=10.2$ ), and were audio-recorded, with participants' permission, for later transcription and analysis.

\section{Analyses of Interview Data}

The interview data were examined using a grounded theory approach supported by the software package, NVivo 8. An overview of the analytic procedures is provided in Figure 1.

[Insert Figure 1 about here]

To begin, a single researcher coded four interviews. In this first cycle of coding, all interview content that referred to behavior was fractured into specific nodes (categories) as they were encountered. Example nodes are: silence, welcome feedback, excuse, not informing, discriminatory behavior based on appearance, smile, unrealistic request, not answering question, attentiveness, intimidation, rumination, and expression of appreciation. An embryonic coding structure was constructed based on these first four interviews. A codebook was devised with definitions, inclusion and exclusion criteria, and exemplars of text representing each node. To illustrate the classification of words, phrases or whole utterances referring to behaviors into free (unconnected) nodes within the framework, reproduced below is an extract from an interview with a university librarian who describes her attempt to assist a female student with photocopying. In this extract, the nodes used to categorize behaviors are given in italics and parentheses:

She wanted to know how to use the photocopier (request assistance). And I watched, I showed her (modeling) and she was already quite upset with the photocopier. And as I was telling her how to program, what to push (procedural instruction), she started pushing the buttons in the middle of it. And she pressed 'Start' and it went to 99 copies. I didn't do it, but she blamed me for it (false accusation). And I said, "Look it's no problem. I can get it refunded for you" (offer refund). But she wasn't happy. 
She started screaming at me (scream/shout), calling me a stupid $\mathrm{xxxx}$ (abuse) and that. And then I said, "I'm going to get somebody to refund you" (seek assistance) ... And I managed to get another staff member to come over. But she was sort of slamming the buttons and that was when it went to 99. And she's the one that pressed 'Start'. I didn't, you know..... And, like I had told her, “Look, don’t worry. It's okay (reassure). We can get the money refunded (offer refund)", because she was very upset (show distress). And I just sort of wanted to calm her down and help. Yeah, but afterwards I left the room and someone else came out, and I stayed out the back (physically withdraw) because I was really upset (show distress).

The remaining interviews were then coded using this frame. Throughout this phase, memos were written, and novel ideas were captured and integrated into the main coding frame. Discussion within the four-person team generated additional ideas and these were fed back into the coding structure until a stable structure reflecting the research aims emerged. As the interview data were coded, free nodes were iteratively organized into tree nodes (that is, inter-connected nodes, classified under super-ordinate categories). Examples of these superordinate (parent) nodes are: question, respond, listen, non-verbal behavior, criticise other, inform, expressive coping, and promise/commit. Examples of subordinate nodes placed under the parent node listening are: active listening, selective listening, pseudo-listening, not listening, and listening generally.

When all interviews were coded, a second coder read the transcripts, coded that which hitherto had been uncoded, checked the integrity of the coding, and noted any discrepancies either in labelling specific behaviors or in allocating these to superordinate (Tier 2) categories. The two coders then discussed these discrepant cases, and assessed their labelling and classification against the final coding structure. Following Miles and Huberman (1994), 
reliability was defined as the number of agreements divided by the total number of instances to be coded, and discussion continued until a reliability criterion of $95 \%$ was achieved. A third coder then resolved the small number of remaining differences. NVivo automated text word searches were also conducted to check on coding, and to identify any behaviors that were not initially detected. These searches yielded few results that had not already been identified, thereby confirming the high quality of the coding process.

In sum, the interview data were decomposed into 272 discrete nodes, all of which pertained to behaviors within service interactions. A further coding process enabled most of these child nodes to be grouped within 30 parent nodes. Examination of this two-tier coding framework suggested that the behavior categories (parent nodes) were not independent of each other. Thus, the final stage of the analysis involved working through the data again, and performing higher-level axial coding to identify overarching themes.

Several general and abstract themes emerged from this re-examination of the interview content. These included distinctions between behaviors that are active versus passive, observable versus unobservable, planned (strategic) versus unplanned (automatic), constructive versus destructive, confrontational/approach versus avoidant, and so on. To evaluate, and choose between these alternatives, explicit criteria were established. Essentially, the aim was to construct a framework comprising constructs that are (a) unambiguous, (b) manageable in number, (c) non-overlapping, and (d) broad in coverage, such that the derived framework can be used to describe, classify, and differentiate between the full range of service encounter behaviors. In addition, the constructs were expected to apply to the actions of service providers and customers, and to have implications for service encounter success. In research team meetings, the fit of each of many possible conceptualizations was assessed against these criteria. Eventually, the team reached 
agreement on a third tier for the framework that comprised the three dimensions of task, relationship, and self, as elaborated below.

\section{The T-R-S Framework of Service Encounter Behaviors}

The interview data contained references to a wide range of behaviors used by employees and customers to handle the routine as well as the more difficult components of service encounters, and to manage themselves during these interactions. The framework that emerged from analysis of these interviews comprises three tiers. At the lowest level (Tier 1) are many hundreds of specific behaviors, nearly all of which are placed within 30 broader (Tier 2) categories. Most of these categories of behavior are performed equally by both parties, although there are exceptions: the Tier 2 category of compensate, for example, is likely to be more often displayed by employees than by customers.

These lower levels of the framework can be interpreted within a conceptual space (Tier 3) defined by three dimensions, namely, the effects the behaviors have on (a) the service task or exchange, (b) the relationship between the parties, and (c) the actor him/herself. Whereas the lower levels represent relatively concrete content domains, the three overarching Tier 3 dimensions represent more abstract functional properties. Behaviors that are high on any of these three dimensions represent an "approach" orientation towards the goal (that is, to the task, relationship or self); a position low on these dimensions represents one that is detrimental to, or avoidant of, that goal. The T-R-S framework is presented in Figure 2, and the opposing poles on each of the Tier 3 dimensions are contrasted in Table 2.

[Insert Figure 2 and Table 2 about here]

The task dimension relates to contributions of behavior to the service exchange. Behaviors characterized as high on this dimension involve employees providing the core service and/or customers receiving or contributing to this service. Behaviors low on this dimension are dysfunctional to the service exchange: they include behaviors in which the 
service is avoided, stalled or undermined. In difficult service encounters, high task-focused behaviors assist with problem resolution and service recovery, whilst behaviors low on this dimension include acts of norm violation, double deviation, and service sabotage. Highly task-focused behaviors tend to be satisfying to customers, and successful task performance may contribute to service employee job satisfaction (Judge, Thoresen, Bono, \& Patton, 2001).

The relationship dimension concerns the contribution of behaviors to the goals, needs or interests of the other party, and thereby to the quality of the relationship between the parties. Behaviors that are characterized as high on this dimension show consideration for the other person, possibly at the (short-term) expense of the self or task; behaviors moderately low on this dimension are those that show indifference to the other person, while those that are extremely low entail harm to the other and/or to the relationship between the parties.

The self dimension relates to the contribution of behaviors to the actor's own goals, needs and interests. Behaviors high on this dimension tend to protect and enhance personal fulfilment and wellbeing; those low on this dimension place strain on the actor because they are difficult, unpleasant and/or resource-depleting. In one sense, all responses can be viewed as furthering personal goals. However, not all behaviors reflect a concern for self that is immediate, primary and direct. Actions that rate low on this dimension are those that involve placing a higher priority on goals and needs other than one's own.

Although best understood in terms of three continuous dimensions, in Figure 2 the framework is also presented as eight domains or segments, four of which (segments 1-4) relate to behaviors that enhance the relationship between the parties, and four (segments 5-8) that damage this relationship. Table 3 gives an example of interviewee responses illustrating each of the eight segments. As shown, these vary from segment 1 behaviors that are problemoriented, yet protective of the actor's own interests and considerate of the other, through to segment 7 behaviors that display a disregard for the task and the other person, plus an 
uncaring or reckless attitude towards the actor's own wellbeing. In between, there is a range of behaviors including, for example, segment 2 behaviors that put the other person and the service delivery/receipt ahead of the actor's own goals, and segment 8 behaviors that satisfy the actor's own needs to the detriment of other considerations. When people adopt these ways of behaving consistently within and across service encounters, segments 1 through 8 of the TR-S framework take the form of distinctive service interaction styles.

[Insert Table 3 about here]

While the service encounter behaviors described in the interviews and represented at Tiers 1 and 2 can be plotted in a space represented by the three T-R-S dimensions, some behaviors have little impact on one or more dimensions of the model and so occupy relatively neutral positions. Other behaviors cannot be classified without additional information regarding their function within the particular service context. For example, humor can be variously used to distract from the task, to enhance the relationship, or to belittle the other person. Interruptions are also difficult to classify: one party may interrupt the other to assist with communication and mutual understanding, or to intimidate the other. Similarly, rules and policies may be invoked to guide, or to block, progress towards task completion. Indeed, many of the specific behaviors coded within the Tier 2 categories of questioning, responding, listening and other parent nodes are highly "situated", and cannot be reliably classified without additional contextual information. Thus, while all actual Tier 2 behaviors can be understood as having task, relationship and self functions, not all can be interpreted, in the absence of contextual details, within the T-R-S framework.

\section{Elaborating, Refining and Verifying the T-R-S Framework}

The robustness of the T-R-S framework was assessed in three ways. First, a systematic literature search was conducted. Key marketing, management, psychology and communication databases (e.g., Business Source Premier, PsychInfo, ScienceDirect) and 
journals published between 1980 and 2011 were searched for lists, typologies and categorical systems pertaining to behaviors performed by customers and/or employees within service encounters. Key search words were service encounter/exchange/interaction/failure/recovery, each combined with behaviors, strategies, approaches, styles, tactics, or responses, and/or combined with difficulties, conflict, stress, emotional labor, incivility, anger, aggression, rage, coping, or emotional regulation. While this search yielded many specific behaviors not previously included in the framework, it did not suggest the need to add or change any Tier 2 (broader categories of behavior) or Tier 3 (abstract dimensions underlying behaviors) components of the framework.

Second, corroboration was sought via a data set that was available as part of another study being conducted by the research team. This comprised a set of 157 audio-recordings of real-life interactions that had taken place over the telephone between a customer and a service employee from one of four very different service organizations (a utility company, an accommodation firm, a local government call center, and a financial services firm). All these dyadic interactions involved some interpersonal tension or conflict and had been selected for study for this reason. They included both in-bound (63\%) and out-bound calls (37\%), and varied in duration from one to 50 minutes. All employee-customer gender combinations were represented. While considerations of social desirability may have constrained the range of behaviors reported in the interview study, the use of this real-time service interaction data to corroborate the T-R-S framework helps overcome this potential limitation.

Content of these interactions had previously been coded using processes similar to the first-cycle coding employed in the interview study. Comparison of the nodes identified in the audio data suggested substantial concurrence with those that emerged from the interviews. More than $95 \%$ of the codes used in the interview study to categorize specific (Tier 1) behaviors were also used in the audio study. While the audio content revealed additional Tier 


\section{Running Head: SERVICE ENCOUNTER BEHAVIORS}

1 behaviors, nearly all of these new behaviors were readily classified into one of the 30 existing Tier 2 categories. The audio data did, however, suggest the need to split four of these categories to allow greater differentiation of similar behaviors. For example, the category of execute core service was split into routine acts of service exchange and seek/providelenact solution to service problem, while the category express (dis)satisfaction/(dis)pleasure was spilt into express positive affect and express negative affect. With these modifications, the framework accommodated this second data set.

The third check on the framework sought to assess the extent to which each of the Tier 2 behavioral categories could be placed along one of the Tier 3 dimensions. Members of an expert panel comprising eight marketing and psychology professors and two doctoral students were asked to assign each of the (now) 34 broad categories of behavior to one of the three dimensions (task, relationship or self), or to indicate that the behavior category belongs equally to a plurality of these dimensions. When the experts' judgments were aggregated, a criterion of $80 \%$ agreement was achieved for 21 of the 34 behaviors. Specifically, at least $80 \%$ of judges believed that eleven behaviors (present the purpose, devote attention to service exchange, inform, instruct, explain, routine acts of service exchange, seek/providelenact solution, compensate, sabotage service exchange, procedure-related, and organization-related) relate mainly to the task dimension, six behaviors (open/close interaction, givelaccept apology, manage discourse, empathise and support, bond with other, and criticize other) pertain mainly to the relationship dimension, and four (active problemfocused coping, expressive/support-seeking coping, escape/avoidance coping, emotionfocused coping) behaviors pertain mainly to the self dimension. The remaining 13 behaviors were less consistently classified, suggesting that they have multiple functions, and/or that their effects vary with other contextual factors. For example, the behavior category promise/commit was classified equally as often as related to the task and to the relationship 
dimensions, while challenge/disagree with other was variously categorized as pertaining to the self and relationship dimensions. Figure 3 presents the full T-R-S framework, including the experts' categorization of the Tier 2 behaviors into Tier 3 dimensions.

[Insert Figure 3 about here]

\section{Comparisons with Prior Work}

In line with the inductive approach adopted, prior theory and research were not used to develop the T-R-S framework. Synergies with this past work are now explored. Examination of the partial typologies, or "mini-theories", of service encounter behavior proposed by past researchers (see Table 1 for examples) indicates that these can be incorporated within the framework. For example, rapport-building behaviors (e.g., Gremler \& Gwinner, 2008) are highly relationship-focused, whereas coping behaviors (e.g., Yi \& Baumgartner, 2004) are highly self-focused. Service sabotage behaviors (e.g., Harris \& Ogbonna, 2002) score low on the task and relationship dimensions. Customer-related social stressors (e.g., Dormann \& Zapf, 2004) would be placed in the low relationship segments of the framework, while the service provider tactics aimed at controlling customers proposed by Rafaeli (1989) would be placed in segment 5 (high task, high self, low relationship). Most service recovery strategies (e.g., Davidow, 2003) and customer orientation strategies (e.g., Rafaeli et al., 2008) would be characterized within the framework as high task/high relationship behaviors. In general, while several past models explicitly or implicitly distinguish between core (task) and relationship dimensions of service exchanges, the T-R-S framework is novel in also giving focus to the "self" dimension.

Another set of ideas related to the current framework is Bateson's (1985) conceptualization of the service encounter as a "three-cornered fight" between the customer, the server, and the service firm. According to Bateson, these three entities have much to gain by working together. However, cooperative efforts are difficult to sustain because the 
interests of the parties conflict, with service firms typically wanting standardization and efficient service delivery, employees seeking job autonomy, and customers wanting flexibility and satisfaction of their individual demands and desires. The three entities, and their diverse interests in the service encounter, although not synonymous, roughly parallel the three dimensions of the framework: task (firm), self, and relationship with the other party.

Pruitt and Rubin's (1986) Dual Concern theory of conflict management styles also supports the T-R-S framework. This theory differentiates approaches to conflict management in terms of two orthogonal dimensions - concern for own outcome and concern for other's outcome - that are similar to two of the three T-R-S higher-order dimensions. While this framework is well regarded and widely used in the conflict management field (De Dreu \& Gelfand, 2008), it applies less well to service encounter behaviors on two counts: it does not explicitly capture participant concern with task performance, and it assumes that concerns for the other party's outcomes vary from neutral to positive, whereas in service interactions, these concerns sometimes fall below the neutral point (Fisk, Grove, Harris, Keeffe, Reynolds, Russell-Bennett, et al., 2011; Harris \& Ogbonna, 2002).

The framework recognizes that, like other social interactions, service encounters have both task and socio-emotional dimensions. At a task level, customers expect to receive a desired service at an agreed price, while employees try to provide the service to standards that at least meet, if not exceed, customer and organizational expectations. As elaborated below, in addition to these instrumental needs, customers and employees share a set of psychosocial needs that must be met for service encounters to be successful. This distinction between task and socio-emotional domains is recognized in many literatures. For example, in the study of human groups, Bales's (1950) Interaction Process Analysis, a widely used tool for analyzing group dynamics, requires coding of utterances into one of six task-related categories or one of six socio-emotional categories. Similarly, in the conflict management literature (e.g., de Dreu 
\& Weingart, 2003), a distinction is made between task conflicts and relationship conflicts, while recent research into conflicts affecting consumers (e.g., Beverland, Kates, Lindgreen, \& Chang, 2010) distinguish between task-framed and personal-framed conflicts.

Models of interpersonal communication also differentiate between a task layer and a meta-communicative (Watzlawik, Beavin, \& Jackson, 1969) or relationship layer (Schulz von Thun, 1981). Watzlawik et al. argued that communication is not limited to just the exchange of (cognitive) information. Both the content of the information exchanged and the manner in which this is done say something about the relationship between the parties, for example, whether they like each other or whether they respect each other's position. The sender's verbalizations, body language, intonation and other nonverbal cues express esteem, respect, friendliness, disinterest, contempt or something else. Extending these ideas, Schulz von Thun argued that in every communication individuals willingly (impression management) or unwillingly (unintended self-revelation) provide information about themselves. Thus, the third (self) dimension of the framework is seen to intersect the other two.

According to Watzlawik et al. (1969) and Schulz von Thun (1981), there is a relationship layer in all social interactions. This layer may remain hidden as long as things go smoothly, only to become apparent when things go wrong. In accord with this, the T-R-S model acknowledges that service problems can occur at both task and socio-emotional levels. For successful service delivery, interactions need to be managed at both levels. Schulz von Thun and Watzlawik et al. have pointed out that conflicts at the relationship level are often acted out at the task level. An example from service interactions is when a customer treats an employee disrespectfully (low relationship behavior), and the employee then withholds from the customer information necessary for problem resolution (low task behavior).

Parallels with the task and self dimensions of the T-R-S framework can also be found in contemporary models of stress (Duhachek, 2005; Lazarus, 1999). When placed in stressful 
situations, service providers and customers must achieve two goals (Schönpflug, 1983). First, there is the goal of solving the problem that led to the stress. Relevant to this goal are behaviors on the task dimension of the T-R-S framework - such as inform, instruct, and seek/provide/enact solutions. Second, stressful situations demand that people protect themselves from negative emotions such as anxiety, tension, and anger. T-R-S self dimension behaviors such as expressive coping, manage own emotions, and escape/withdraw are located here. Theories of coping (e.g., Lazarus \& Folkman, 1984) distinguish between problemfocused and emotion-focused coping strategies, a distinction that reflects the differentiation between concern for stressor (task) management and concern for self-management.

The emotional labor literature can also be linked to the current framework. The concept of emotional labor or emotion work was introduced to describe social interactions in service encounters (Grandey, 2000; Hochschild, 1983; Zapf, 2002). According to this literature, firms expect employees to display organizationally desired emotions, for example, by being friendly to customers and showing enthusiasm. Service work can be understood in terms of a dual task model, with the service delivery/receipt as the primary task, and the management of the relationship through emotion work as the secondary task (Zapf, 2002). The emotion regulation strategies used (or not) to carry out this secondary task fall along the relationship dimension of the framework.

Hochschild (1983) identified several strategies used to regulate emotions in accord with organizational display rules. Surface acting refers to modifying an emotional expression after the emotion has been experienced, by suppressing, faking, or amplifying a response (Grandey, 2000; Gross, 2002). In contrast, deep acting involves attempts to actually feel the emotion displayed. The empirical literature has shown that deep acting is related to organizational success and wellbeing of the service provider, whereas surface acting is less successful in that it poses a greater threat to actor wellbeing (Bono \& Vey, 2005; Hülsheger 
\& Schewe, 2011; Zapf, 2002). In terms of the current framework, deep acting is high in both self-focus and relationship-focus, whereas surface acting is high in concern for the relationship but indicates little concern for self, as it implies emotion suppression which has negative consequences for the individual (e.g., Gross, 2002; Hopp, Rohrmann, Zapf, \& Hodapp, 2010). The related concept of emotional deviance - which occurs when an individual neither feels nor shows organizationally-prescribed emotions - is low in both concern for self and concern for relationship as it implies confronting the interaction partner with negative emotions in ways that also have negative consequences for the self (Tschan, Rochat, \& Zapf, 2005).

Finally, links can be drawn between the current framework and Service Encounter Needs Theory (SENT: Bradley, McColl-Kennedy, Sparks, Jimmieson, \& Zapf, 2010). According to this theory, the effects of service encounter behaviors on participant outcomes are mediated by satisfaction (or not) of a set of eight psychosocial needs. These needs may be roughly ordered along a dimension from, at one pole, those that relate mainly to task/utilitarian matters (needs for cognition, competence, control, and justice) to, at the other pole, those that pertain mainly to socio-emotional matters (needs for power, respect, trust, and pleasing relations). These needs are satisfied to varying extents in different social, including service, situations. From the perspective of the T-R-S framework, different kinds of behaviors - task, relationship, or self-focused - are likely to impact different needs in different (positive or negative) ways. Outcomes such as participant satisfaction, strain, and loyalty are dependent on the extent to which behaviors lead to need fulfillment (and hence favourable outcomes) or violation (and hence negative reactions). SENT thus provides an explanation of the mechanism through which T-R-S behaviors are likely have their effects.

In sum, there is evidence of convergent validity in these synergies between the current framework and the ideas, models and theories proposed in the past. The framework extends 
past work in several ways. It is unique not only in incorporating the three dimensions, but also in its capacity to describe service encounter dynamics, and to identify the likely effects of particular behaviors on service interaction outcomes. Key theoretical and managerial applications of the T-R-S framework are elaborated below.

\section{Applying the T-R-S Framework in Practice}

The T-R-S framework has several possible applications. First, it can be used to describe (label) a single behavior in a single service encounter. Such descriptions can be made at one, two, or all three levels of abstraction. Second, it can be used to represent the characteristic way in which a person behaves across an entire interaction, or to plot the way the person typically behaves across multiple service interactions. As such, the framework can capture an individual's distinctive service interaction style. Third, the framework can be used to describe the behaviors of both parties and thereby increase understanding of the dynamics of service interactions. Very different sorts of processes and outcomes may occur if, for example, both parties behave in ways that are high on task, relationship, and self dimensions than if only one party behaves in these ways.

Fourth, the framework can be used to examine the way in which an interaction unfolds over time. This might involve dividing the interaction into several time periods, and using the T-R-S framework to plot each party's modal behavior during each period. To identify patterns of problem escalation and de-escalation over time, the ratio of "positive" to "negative" Tier 2 behaviors within each period could be calculated. These counts of positive and negative behavior may include all three dimensions, or may be limited to just the task dimension (e.g., the number of behaviors in the categories of seek/provide solution to service problem versus sabotage service) or just the relationship dimension (e.g., build bonds, empathise/support, and apologizelforgive versus challenge other and criticize other). Specific 
triggers of problem escalation and de-escalation may then be pinpointed from within each behavior category.

Drawing upon the interview data and past services literature, and using the rubric of the T-R-S framework, several propositions can be offered to describe normative service interactions. Examples of such normative propositions are:

Proposition 1: Most short, simple service encounters are dominated by task-focused behaviors, especially the Tier 2 behavior categories of question, respond, inform, instruct, and routine service exchange.

Proposition 2: Many service interactions unfold in a sequence in which predominantly relationship-focused behaviors are followed by a period of mainly task behaviors, before the interaction closes with a brief exchange of relationship behaviors.

Proposition 3: As the duration of service encounter increases, an increasing proportion and wider range of relationship behaviors are evident. (In this sense, as their duration increases, service encounters become more like other "human" encounters).

Proposition 4: As service encounters increase in complexity, self-focused behaviors become more evident.

Proposition 5: Behaviors that are high on the relationship dimension occur most often when "regular" customers interact with long-term employees.

Proposition 6: Behaviors that are high on the self dimension are most in evidence when the participants are threatened or placed under stress.

In addition to its role as a tool for describing service encounters, the T-R-S framework provides a framework through which to understand the likely efficacy of specific behaviors and the subsequent success of entire service encounters. Here, success is defined broadly to include outcomes that satisfy all parties - customer, employee and organization. Not all 
service encounters are successful in this sense: some result in dissatisfaction, stalemate, or escalating levels of conflict and negativity. Understanding the reasons for these dissatisfactory outcomes is critical to service firm performance, and the framework can assist. The discussion that follows explores possible linkages between T-R-S behaviors and successful service interactions.

A reasonable premise from which to begin identifying the critical ingredients of service interaction success is to acknowledge the potential dangers associated with behaviors that are low on each of the T-R-S dimensions. In general, the service climate (e.g., Brown \& Lam, 2008; Drach-Zahavy, 2010), service encounter (e.g., Beverland et al., 2010; Bitner et al., 1990, 1994; Rafaeli et al., 2008; Sideman Goldberg \& Grandey, 2007), and service recovery (e.g., Davidow, 2003; Gelbrich \& Roschk, 2011; Wirtz \& Mattila, 2004) literature supports the following conclusions. First, behaviors that are low on the task dimension are likely to lead to participant frustration and dissatisfaction, and limited organizational efficiency and productivity. Second, behaviors that are low on the relationship dimension adversely affect the quality of the bond between the actor and the other party, and, in turn, the bond between the actor and the service firm. Customer switching and negative word-ofmouth, and employee alienation and withdrawal, are likely cumulative effects of a preponderance of such behaviors. Third, behaviors that are low on the self dimension eventually lead to reduced participant wellbeing. Thus, behaviors at the low end of one or more of the T-R-S dimensions increase the likelihood that customers will walk out, and/or employees will burn out.

It follows that behaviors that are high on all three dimensions (segment 1 behaviors in the framework) are most likely to facilitate successful outcomes from service encounters. As Harris and Ogbonna (2002) said, "successful service delivery is likely to require a delicate balance between firm, customer and employee needs" (p. 178). Such behaviors tend to reflect 
that balance, and hence maximize chances of "win-win-win" outcomes, because they seek to effect service exchanges and solve service problems in ways that protect the interests of all parties. Many of the behaviors mentioned by the interviewees that can be categorized in this segment involve some combination of thinking laterally, showing initiative, "reaching out" to the other party, and sharing the leadership role. Segment 1 behaviors thus tend to involve the parties working with each other as joint problem-solvers and co-creators of value (McCollKennedy et al., 2012). When these conditions hold, there is little likelihood of the destructiveness that characterize some segment 7 behaviors, or the self-defensiveness evident in some segment 8 behaviors.

Given that segment 1 behaviors are in general the most efficacious, it follows that behaviors which are high on at least two, but not on all three, of the dimensions - that is, segments 2, 4, and 5 - will generally yield more satisfactory outcomes than will those low on two or more dimensions. However, segments 2, 4, and 5 are likely to produce outcomes that are desirable and undesirable in different ways. For example, behaviors that enable tasks to be performed in ways that satisfy the customer but not the employee (segment 2) may eventually lead to employee job strain, absenteeism and turnover, whereas those that involve the employee performing the task in ways that are personally but not mutually satisfying (segment 5) may result in customer negative word of mouth and disloyalty. The behaviors that are high on only one dimension (segments 3,6 and 8) seldom facilitate service encounter success. At the far extreme, behaviors that are low on all three dimensions (segment 7) are, almost by definition, bound to produce the least satisfactory outcomes.

Several contradictions were apparent in the behaviors recommended by interviewees. For example, many respondents advocated adopting a friendly approach (high relationship behaviors), but some were wary of over-stepping the mark into inappropriate informality or unprofessionalism (but not too high). Similarly, some employees recommended behaving in 
self-confident and positive ways (high self behaviors), but also admitting one's mistakes and apologizing, where appropriate (low self behaviors), Likewise, service employees thought it best to (a) take responsibility (“own the problem"), but also delegate, escalate or refer sideways, if needed, (b) consider the needs of individual customers, but also be consistent when dealing with all, (c) empathize, but not get personally involved, (d) build and maintain pleasant relationships, but also stand one's ground (e.g., by denying customer requests), and (e) acknowledge that the other has been harmed, but also remain loyal to the organization and not place blame on co-workers. As this list shows, service encounters frequently expose employees - and perhaps customers - to difficult-to-resolve dilemmas, and require them to choose between potentially incompatible options, each of which may have merit.

Both the interview data and the emergent framework suggest that good outcomes from service encounters are most likely to be achieved when the parties shift their approach away from the unproductive behaviors that are represented by segment 7 (and, to a lesser extent, segments 6 and 8) to more constructive behaviors belonging especially to segment 1 . However, the contradictions described above make clear the importance of adopting a flexible approach in service encounters, with several interviewees noting that not all circumstances call for segment 1 behaviors. At times, therefore, it may be appropriate to behave in ways that de-emphasize goals pertaining to the self (segment 2), the task (segment 4), or the relationship (segment 5). One factor suggested as critical in determining the likely efficacy of these alternative behaviors is the phase (for example, early, middle or late) within the particular encounter, with several interviewees commenting that single behaviors may have diverse effects depending on their timing. Past service encounter research (e.g., Rafaeli et al., 2008) makes a similar point. The issue is not so much if employees should be friendly or formal, flexible or consistent, and so on, but when they should behave in each of these ways. The following interview extracts illustrate this point: 
If somebody is really nervous and starts to increase the level of their voice, the pitch, it is very clear they are actually going out of control. So if [the employyee] remains very calm and says, "I can understand what you're saying", it can sometimes be exasperating for the customer. But it's a question of getting the mix right and knowing that this is not the point at which to say, "Oh yes, I completely understand". .... It's about the timing of those responses ... So if this customer is right in the flurry of their angry interaction and you say, "I completely understand", if you say that too soon, then you actually increase the level of aggression by the customer because, no, you don't understand. (Manager, utility company)

One of the biggest mistakes is that they [employees] try to jump in with a solution too quickly ... They are taking similar types of calls and they might get similar types of questions, but just because they've heard that question being asked fifty thousand times doesn't mean that the answer that they're going to give is always the right one. They need to take stock and listen. (Supervisor, insurance company)

The idea that the impact of many behaviors varies with their timing can be extended to a acknowledgement that behavior efficacy also varies from customer to customer, from employee to employee, and from issue to issue. Together, these contextual dependencies reinforce the idea that the parties need to adopt a flexible (contingency) approach in their selection of service encounter behaviors.

Drawing together the arguments presented to date, and supported by consideration of both the interview content and the services marketing and broader literatures partly reviewed above, the following prescriptive propositions are provided regarding the likely effects of task, relationship and self behaviors on service interaction outcomes. 
Proposition 7: To be successful, most short and simple interactions require the parties to do no more than display appropriate task-focused behaviors, with the encounter possibly "book-ended" by perfunctory relationship behaviors.

Proposition 8: In more complex interactions, service encounter success requires employees to display a mix of task-, relationship- and self-focused behaviors. Neglect of any one of these dimensions of behavior has adverse short-term effects on customer, employee and/or organizational outcomes.

Proposition 9: Different service contexts require different balances of these behavior types. For example, busy contexts and time-limited interactions demand a majority of task behaviors; interactions involving the exchange of credence services require disproportionately high amounts of relationship behaviors; complaint-related and other emotionally-charged encounters require self-protective behaviors.

Proposition 10: Service interaction success depends on the timing of particular behaviors in the context of particular interactions. For example, in the early phases of difficult interactions, service providers may need to use relatively passive segment 3 (high relationship, low task and low self) behaviors, and move towards behaviors from segment 1 only as the interaction progresses.

Propositions 7-10 indicate the likely effects of the three T-R-S dimensions in quite general terms. It is also possible to offer more specific propositions that differentiate between particular outcomes related to the focal person, the other party, and the organization. For example, as noted, employee behaviors that are high on the task dimension - for example, behaviors from the Tier 2 categories of attend to task, inform, explain, and seek/provide solutions - are functional for both the customer and the service firm. Therefore: 
Proposition 11: High employee task-focused behaviors are positively related to (a) customer satisfaction and (b) organizational performance.

Employee behaviors that are high on the relationship dimension (e.g., behaviors from the Tier 2 categories of build bonds, empathize/support and give/accept apology) tend to fulfil the psychosocial needs of customers (Bradley et al., 2010), and, through this, contribute to customer satisfaction. Therefore:

Proposition 12a: Employee behaviors that are high in relationship focus are positively related to customer satisfaction.

As customer satisfaction contributes to customer loyalty (Wirtz \& Mattila, 2004), and customer loyalty is positively related to the financial performance of service organizations (Loveman, 1998), it follows that:

Proposition 12b: Employee behaviors that are high in relationship focus are positively related to organizational performance.

The consequences for employees' own wellbeing of behaving in ways that are high on the relationship dimension are less straightforward. On the one hand, building strong relations with customers may have a positive effect on service providers, in part because employee needs for competence and pleasing relations are met. However, building positive relations may require using strategies such as surface acting that are stress-inducing (Brotheridge \& Grandey, 2002). If relationship behaviors are exhibited at the expense of the individual's coping resources (that is, a high relationship focus is combined with low concern for self), then they will likely have negative effects on employee wellbeing (Bakker, Demerouti, \& Euwema, 2005; Drach-Zahavy, 2010; Zapf, 2002). Therefore, rather than a simple main effect on employee wellbeing, an interaction effect may apply. 
Proposition 13a: The effects of relationship-focused employee behaviors on employee wellbeing are moderated by concern for self. The effects will be negative if concern for self is low, and positive if self-focus is high.

The impact of a high task-focus on employees is similarly complicated. Engaging in highly task-focused behaviors generally means doing a good job. This may help fulfil employee needs for competence and control, and may thus have positive effects on employee wellbeing (Bradley et al., 2010). However, high task-focus may involve being available to customers on a 24-hour basis, or performing demeaning or stressful tasks, and these can have deleterious effects on wellbeing. Therefore, task focus is likely to interact with self focus to affect employee wellbeing.

Proposition 13b: The effects of task-focused employee behaviors on employee wellbeing are moderated by self-focused behaviors. The effects will be negative if self-focus is low, and positive if self-focus is high.

The effects of self-focused behaviors on the actor's wellbeing are, by definition, positive. However, the effects of self-focused employee behaviors on customer satisfaction and on organizational performance are dependent on the other dimensions within the framework. While high self-focus can mean that the interests of the customer and the organization are ignored, if task focus and relationship focus are high, self-focused employee behaviors may have positive effects on customers and organizations. Thus:

Proposition 14: The effects of self-focused employee behaviors on customer satisfaction and organizational performance are moderated by (a) task and (b) relationship focus. The effects will be negative if task (relationship) focus is low, and positive if task (relationship) focus is high.

The latter propositions underscore the dyadic nature of the T-R-S framework: they show that effects on customers are more positive when the service provider's self interest is also met. 
This reflected in, for example, the frequently found positive relationship between employee job satisfaction and customer satisfaction (e.g., Harter, Schmidt, \& Hayes, 2002; Homburg \& Stock, 2005). Conversely, the framework implies that employee attempts to maximize self interest at the expense of the customer are less positive for the service provider than are behaviors that maximize the interests on both parties. The central proposition is that all three dimensions of behavior contribute to making service encounters successful.

To shift service encounter behavior towards an appropriate mix of task, relationship and self, service firms could intervene at multiple levels. In particular, there may be a need to educate customers (so that, for example, they enter service encounters holding realistic expectations of the service exchange, positive attitudes to their interaction partner, and ample knowledge to fulfil their role competently), train employees (so that they possess the skills necessary to perform segment 1 behaviors), and change organizational systems and structures (so that resources are in place, and constraints are removed, thereby enabling and encouraging employees to deploy appropriate service interaction behaviors).

As part of staff training and performance-management initiatives, the T-R-S framework can be used to give feedback to employees regarding behaviors that have been under- and/or over-used in past interactions. Supervisors may use the language of this framework when diagnosing problems in employee behavior and when discussing with their front-line employees alternative ways of responding to interaction difficulties. This information can thus increase employee awareness of their own behaviors and of the consequences of these actions. Staff training may involve pursuit of two broad objectives equipping employees with behaviors to implement in those service encounter circumstances that can be predicted in advance, as well as equipping them with more generic competencies to deal effectively with the unexpected. The T-R-S framework can help pinpoint specific behavioral deficits and provide guidance in the acquisition of broader competencies. 


\section{Running Head: SERVICE ENCOUNTER BEHAVIORS}

\section{Directions for Future Research}

The T-R-S framework was derived and cross-checked using multiple research methods. It provides a means of organizing empirical material and a platform upon which future studies of service encounter behaviors can be based. Several recommendations for further research may be offered. First, work is required to test the robustness of the framework and particularly assess the extent to which service encounter behaviors can be reliably coded into the Tier 2 categories and along the Tier 3 dimensions. Second, research should differentiate between service encounter behaviors using the dimensions of the T-R-S framework and examine outcomes associated with each behavior type. Propositions 7-14, above, are examples of hypotheses worthy of testing. Also worthy of investigation are issues relating to the prevalence of stable service interaction styles corresponding to T-R-S segments 1 through 8 , and the consequences of adopting each of these styles. In addition, more complex dyadic hypotheses can be derived from the T-R-S framework and investigated in future research. Researchers could, for example, examine levels of satisfaction and/or stress when one party's behaviors are predominantly in segment 2 (high self- and relationship-focus, but low in task-focus) while the other's behavior is predominantly from segment 3 (high self- and task-focus but low in relationship-focus). Finally, given that the efficacy of service encounter behaviors depends on a range of extra- and intra-interaction factors (e.g., service sector, participant characteristics, prior relationship quality, elapsed time), future research could assess the ways in which these moderating variables interact with components of the framework.

\section{Conclusion}

Past contributions to knowledge about service encounter behaviors have been piecemeal: bits of the jig-saw are in place, but others are missing, as is a sense of how the pieces fit together. To address these deficiencies, this paper presented a triadic 
conceptualization of service encounter behaviors deigned to provide coherence to the field. Development of the T-R-S framework began with an interview-based study that identified 272 specific service encounter behaviors. Most of these were organized into a conceptual structure represented, at an intermediate level, by broader categories of behavior content, and, at a more abstract level, by three functional dimensions. The framework was then elaborated and confirmed using extant literature, recordings of actual service interactions, and an expert panel, and the framework was shown to have several synergies with prior theoretical and empirical work.

The T-R-S framework helps systematize knowledge of service encounter behavior. A firmer conceptual grasp of these behaviors, and a shared lexicon to describe them, should assist service employee training and performance management, and, ultimately, help improve service delivery. The three-tier framework also offers insights into the behaviors most likely to be associated with satisfactory and dissatisfactory customer, employee and organizational outcomes. As has been argued, understanding the effects of behavior on service encounter success and failure is likely to require an appreciation not only of the interactive effects of task, relationship and self behavioral dimensions, but also of their individual and joint dependency on contextual factors and on timing within the interaction. 


\section{Running Head: SERVICE ENCOUNTER BEHAVIORS}

\section{References}

Bakker, A. B., Demerouti, E., \& Euwema, M. C. (2005). Job resources buffer the impact of job demands on burnout. Journal of Occupational Health Psychology, 10, 170-180.

Bales, R. F. (1950). Interaction process analysis: A method for the study of small groups. Reading, Massachusetts: Addison-Wesley.

Bateson, J. E. G. (1985). Perceived control and the service encounter. In J. A. Czepiel, M. R. Solomon, \& C. F. Surprenant (Eds.), The service encounter: Managing employee/customer interaction in service businesses (pp. 67-82). Lexington: Lexington Books.

Beverland, M. B., Kates, S. M., Lindgreen, A., \& Chang, E. (2010). Exploring consumer conflict management in service contexts. Journal of the Academy of Marketing Science, 38, 617-633.

Bitner, M. J., Booms, B. H., \& Mohr, L. A. (1994). Critical service encounters: The employee's viewpoint. Journal of Marketing, 58, 95-106.

Bitner, M. J., Booms, B. H., \& Tetreault, M. S. (1990). The service encounter: Diagnosing favorable and unfavorable incidents. Journal of Marketing, 54, 71- 84.

Bono, J., \& Vey, M. (2005). Toward understanding emotional management at work: A quantitative review of emotional labor research. In C. E. Härtel \& W. J. Zerbe (Eds.), Emotions in organizational behavior (pp. 213-233). Mahwah: Erlbaum.

Bradley, G. L., McColl-Kennedy, J. R., Sparks, B. A., Jimmieson, N. L., \& Zapf, D. (2010). Service encounter needs theory: A dyadic, psychosocial approach to understanding service encounters. In W. J. Zerbe, C. E. J. Hartel, \& N. M. Ashkanasy (Eds.), Research on emotions in organizations. Volume 6. Emotions and creativity, learning, change and development (pp. 221-258). Bingley. UK: Emerald Group Publishers/JAI. 
Brotheridge, C. M., \& Grandey, A. A. (2002). Emotional labor and burnout: Comparing two perspectives of “people work”. Journal of Vocational Behavior, 60, 17-39.

Brown, S. P., \& Lam, S. K. (2008). A meta-analysis of relationships linking employee satisfaction to customer responses. Journal of Retailing, 84, 243-255

Corbin, J., \& Strauss, A. (2008). Basics of qualitative research: Techniques and procedures for developing grounded theory ( $3^{\text {rd }}$ ed.). Thousand Oaks: Sage.

Côte, S. (2005). A social interaction model of the effects of emotion regulation on work strain. Academy of Management Review, 30, 509-530.

Davidow, M. (2003). Organizational responses to customer complaints: What works and what doesn't. Journal of Service Research, 5, 225-250.

De Dreu, C. K. W., \& Gelfand, M. J. (Eds.) (2008). The psychology of conflict and conflict management in organizations, New York: Lawrence Erlbaum.

De Dreu, C. K. W., \& Weingart, L. R. (2003). Task versus relationship conflict, team performance, and team member satisfaction: A meta-analysis. Journal of Applied Psychology, 88, 741-749.

Dormann, C., \& Zapf, D. (2004). Customer-related social stressors and burnout. Journal of Occupational Health Psychology, 9, 61-82.

Drach-Zahavy, A. (2010). How does service workers' behavior affect their health? Service climate as a moderator in the service behavior-health relationship. Journal of Occupational Health Psychology, 15, 105-199

Duhachek, A. (2005). Coping: A multidimensional, hierarchical framework of responses to stressful consumption episodes. Journal of Consumer Research, 32, 41-53.

Fisk, R., Grove, S., Harris, L. C., Keeffe, D., Reynolds, K., Russell-Bennett, R., \& Wirtz, J. (2011). Customers behaving badly: A state of the art review, research agenda, and implications for practitioners. Journal of Services Marketing. 24, 417-429. 
Gelbrich, K., \& Roschk, H. (2011). A meta-analysis of organizational complaint handling and customer responses. Journal of Service Research, 14, 42-43.

Goodwin, C., \& Ross, I. (1992). Consumer responses to service failures: Influence of procedural and interactional fairness perceptions. Journal of Business Research, 25, $149-163$.

Grandey, A. A. (2000). Emotion regulation in the workplace: A new way to conceptualize emotional labor. Journal of Occupational Health Psychology, 5, 59-100.

Gregoire, Y., \& Fisher, R. J. (2008). Customer betrayal and retaliation: When your best customers become your worst enemies. Journal of the Academy of Marketing Science, $36,247-261$.

Gremler, D. D., \& Gwinner, K. P. (2008). Rapport-building behaviors used by retail employees. Journal of Retailing, 84, 308-324.

Gross, J. J. (2002). Emotion regulation: Affective, cognitive, and social consequences. Psychophysiology, 39, 281-291.

Harris, L. C., \& Ogbonna, E. (2002). Exploring service sabotage: The antecedents, types and consequences of frontline, deviant, antiservice behaviors. Journal of Service Research, 4, 163-183.

Heskett, J. L., Sasser, W. E., \& Schlesinger, L. A. (1997). The service profit chain. New York: Free Press.

Hochschild, A. R. (1983). The managed heart: Commercialization of human feelings. Berkeley, CA: University Press.

Harter, J. K., Schmidt, F. L., \& Hayes, T. L. (2002). Business-unit-level relationships between employee satisfaction, employee engagement, and business outcomes: A meta-analysis. Journal of Applied Psychology, 87, 28-279. 
Homburg, C., \& Stock, R. M. (2005). Exploring the conditions under which salesperson work satisfaction can lead to customer satisfaction. Psychology \& Marketing, 22, 393-420.

Hopp, H., Rohrmann, S., Zapf, D., \& Hodapp, V. (2010). How emotional dissonance affects psychophysiology in a face-to-face service interaction and the moderating role of gender and personality. Anxiety, Stress \& Coping, 23, 399-414.

Hülsheger, U. R., \& Schewe, A. F. (2011). On the costs and benefits of emotional labor: A meta-analysis of three decades of research. Journal of Occupational Health Psychology, 16, 361-389.

Judge, T. A., Thoresen, C. J., Bono, J. E., \& Patton, G. K. (2001). The job satisfaction-job performance relationship: A qualitative and quantitative review. Psychological Bulletin, 127, 376-407.

Lazarus, R. S. (1999). Stress and emotion. A new synthesis. New York: Springer.

Lazarus, R. S., \& Folkman, S. (1984). Stress, appraisal and coping. New York: Springer.

Loveman, G. W. (1998). Employee satisfaction, customer loyalty, and financial performance: An empirical examination of the service profit chain in retail banking. Journal of Service Research, 1, 18-31.

McColl-Kennedy, J. R., Patterson, P. G., Smith, A. K., \& Brady, M. K. (2009). Customer rage episodes: Emotions, expressions and behaviors. Journal of Retailing, 85, 222237.

McColl-Kennedy, J. R., Vargo, S. L., Dagger, T. S., Sweeney, J. C., \& van Kasteren, Y. (2012). Health care customer value cocreation practice styles. Journal of Service Research, 15, 370-389.

Miles, M. B., \& Huberman, A. M. (1994). Qualitative data analysis: An expanded sourcebook ( $2^{\text {nd }}$ ed.). Thousand Oaks, CA: Sage. 
Nyquist, J. D., Bitner, M. J., \& Booms, B. H. (1985). Identifying communication difficulties in the service encounter: A critical incident approach. In J. A. Czepiel, M. R. Solomon, \& C. F. Surprenant (Eds.), The service encounter: Managing employee/customer interaction in service businesses (pp. 195-212). Lexington: Lexington Books.

Ostrom, A. L., Bitner, M J., Brown, S. W., Bunkhard, K. A., Goul, M., Smith-Daniels, V. et al. (2010). Moving forward and making a difference: research priorities for the Science of Service. Journal of Service Research, 13, 4-36.

Payne, A. F., Storbacka, K., \& Frow, P. (2008). Managing the co-creation of value. Journal of the Academy of Marketing Science, 36, 83-96.

Pruitt, D. (1983). Strategic choice in negotiation. American Behavioral Scientist, 27, 167-194.

Rafaeli, A. (1989). When cashiers meet customers: An analysis of the role of supermarket cashier. Academy of Management Journal, 32, 245-273.

Rafaeli, A., Ziklik, L., \& Doucet, L. (2008). The impact of call center employees' customer orientation behaviors on service quality. Journal of Service Research, 10, 239-255.

Reynolds, K. L., \& Harris, L. C. (2006). Deviant customer behaviour: An exploration of frontline employee tactics. Journal of Marketing Theory and Practice, 14, 95-111.

Schönpflug, W. (1983). Coping efficiency and situational demands. In G. R. J. Hockey (Ed.), Stress and fatigue in human performance (pp. 299-330). Chichester: Wiley.

Schulz von Thun, F. (1984). Psychologische Vorgänge in der zwischenmenschlichen Kommunikation (Psychological processes in communication between humans). In B. Fittkau, H-M. Müller-Wolf \& F. Schulz von Thun (Eds.), Kommunizieren lernen (und umlernen) (Learning (and re-learning) to communicate) (pp. 9-100). Braunschweig: Agentur Pedersen. 
Sideman Goldberg, L., \& Grandey, A. (2007). Display rules versus display autonomy: Emotion regulation, emotional exhaustion, and task performance in a call center simulation. Journal of Occupational Health Psychology, 12, 301-318.

Sparks, B. (2001). Managing service failure through recovery. In J.Kandampully, C. Mok \& B. Sparks (Eds.), Service quality management in hospitality, tourism and leisure (pp. 193-219). New York: Haworth.

Sparks, B. A., \& McColl-Kennedy, J. R. (2001). Justice strategy options for increased customer satisfaction in a service recovery setting. Journal of Business Research, 54, 209-218.

Sundaram, D. S., \& Webster, C. (2000). The role of nonverbal communication in service encounters. Journal of Services Marketing, 14, 378-391.

Svensson, G. (2006). New aspects of research into service encounters and service quality. International Journal of Service Industry Management, 17, 245-257.

Tschan, F., Rochat, S., \& Zapf, D. (2005). It's not only clients: Studying emotion work with clients and co-workers with an event-sampling approach. Journal of Occupational and Organizational Psychology, 78, 195-220.

Varca, P. E. (2009). Emotional empathy and front line employees: Does it make sense to care about the customer? Journal of Services Marketing, Vol. 23, No. 1, pp. 51-56.

Vargo, S., \& Lusch, R. F. (2004). Evolving to a new dominant logic for marketing. Journal of Marketing, 68, 1-17.

Watzlawick, P., Beavin, J. H., \& Jackson, D. D. (1969). Pragmatics of human communication. New York: Norton.

Weatherley, K. A., \& Tansik, D. A. (1993). Tactics used by customer-contact workers: Effects of role stress, boundary spanning and control. International Journal of Service Industry Management, 4, 4-17. 
Wirtz, J., \& Mattila, A. S. (2004). Consumer responses to compensation, speed of recovery and apology after a service failure. International Journal of Service Industry Management, 15, 150-166.

Yi, S., \& Baumgartner, H. (2004). Coping with negative emotions in purchase-related situations. Journal of Consumer Psychology, 14, 303-317.

Zapf, D. (2002). Emotion work and psychological well-being. A review of the literature and some conceptual considerations. Human Resource Management Review, 12, 237-268. 
Table 1

Examples of Past Categorizations of Service Interaction Behaviors

\begin{tabular}{|c|c|c|c|c|}
\hline $\begin{array}{l}\text { Author } \\
\text { (and year) }\end{array}$ & $\begin{array}{l}\text { Method Used to } \\
\text { Develop } \\
\text { Framework }\end{array}$ & Actor & $\begin{array}{l}\text { Category of } \\
\text { Behavior }\end{array}$ & $\begin{array}{l}\text { Examples of Dimensions, Narrow Categories, } \\
\text { and/or Specific Behaviors Identified }\end{array}$ \\
\hline Davidow (2003) & $\begin{array}{l}\text { Literature review \& } \\
\text { questionnaire-based } \\
\text { study }\end{array}$ & $\begin{array}{l}\text { Employee/ } \\
\text { organization }\end{array}$ & $\begin{array}{l}\text { Organizational } \\
\text { responses to } \\
\text { consumer } \\
\text { complaints }\end{array}$ & $\begin{array}{l}\text { Six dimensions of response: timeliness, apology, redress, } \\
\text { facilitation, credibility, and attentiveness. }\end{array}$ \\
\hline $\begin{array}{l}\text { Dormann and Zapf } \\
\text { (2004) }\end{array}$ & $\begin{array}{l}\text { Literature review } \\
\text { and empirical } \\
\text { methods for scale } \\
\text { development }\end{array}$ & Customer & $\begin{array}{l}\text { Customer-related } \\
\text { social stressors }\end{array}$ & $\begin{array}{l}\text { Four themes: disproportionate customer expectations, customer } \\
\text { verbal aggression; disliked customers, and ambiguous } \\
\text { customer expectations. }\end{array}$ \\
\hline $\begin{array}{l}\text { Gremler and } \\
\text { Gwinner (2008) }\end{array}$ & $\begin{array}{l}\text { Literature review \& } \\
\text { critical incident } \\
\text { technique with } \\
\text { samples of } \\
\text { employees and } \\
\text { customers }\end{array}$ & $\begin{array}{l}\text { Employee } \\
\text { (or customer) }\end{array}$ & $\begin{array}{l}\text { Rapport-building } \\
\text { behaviors }\end{array}$ & $\begin{array}{l}\text { Five categories: (a) Uncommonly attentive behaviors (e.g., } \\
\text { personal recognition, intense personal interest), (b) Common } \\
\text { grounding behavior (e.g., identifying mutual interests; finding } \\
\text { other similarities), (c) Courteous behaviors (e.g., unexpected } \\
\text { honesty, civility), (d) Connecting behaviors (e.g., using } \\
\text { humour, pleasant conversation), and (e) Information sharing } \\
\text { behavior (e.g., giving advice, asking questions). }\end{array}$ \\
\hline $\begin{array}{l}\text { Harris and } \\
\text { Ogbonna (2002) }\end{array}$ & $\begin{array}{l}\text { Literature review \& } \\
\text { interviews with } \\
\text { hospitality } \\
\text { employees }\end{array}$ & Employee & $\begin{array}{l}\text { Service sabotage } \\
\text { behaviors }\end{array}$ & $\begin{array}{l}\text { Behaviors range along two dimensions: from overt to covert } \\
\text { and from intermittent to routinized. They include slowing } \\
\text { down the service, by-passing customer-oriented procedures, } \\
\text { patronise/belittle/condescend to customers, over-adherence to } \\
\text { bureaucratic/annoying rules, accidental clumsiness, and } \\
\text { colluding with colleagues to disrupt service. }\end{array}$ \\
\hline
\end{tabular}


Rafaeli (1989)

Multiple qualitative methods, including

observations and

interviews.

Rafaeli, Ziklik and

Doucet (2008)

Reynolds and

Harris (2006) ${ }^{\mathrm{a}}$

Sparks (2001)

Sundaram and

Webster (2000)

Varca (2009) and managers.
Qualitative analyses Employee of 166 telephone

service interactions.

Interviews with

restaurant staff:

frontline employees

Literature review

Employee

Literature review

Employee

Focus groups with

60 frontline

employees

Employee

Employee
Employee

Strategies for controlling interactions with customers

Customer orientation

behaviors

Tactics for dealing with poorly behaved customers

Service recovery strategies

Non-verbal behaviors

Emotionallyladen job behaviors
Ignoring customers; rejecting customers' right to control; reacting to customers' attempt at control; and engaging customers so that they don't seek control.

Anticipating customer requests, educating customers, offering explanations/justifications, providing emotional support, offering personalized information.

Ignoring difficult customers; bribing customers; using emotional labour; exploiting sexual attractiveness; eliciting support from patrons; altering speech patterns; manipulating the servicescape.

In addition to non-recovery actions (denial and avoidance), strategies are: fix the problem/replacement, apology, explanation, invite customer input (voice), and compensation.

Four channels: kinesics (body orientation and body movement); paralanguistics (including vocal pitch, volume, rate and amplitude); proxemics (including touch and distance); physical appearance (including attractiveness, dress).

Showing patience with frustrated customers; showing courtesy and manners; showing empathy and expressing regret; developing rapport; withholding own frustrations; interacting with angry customers; handling rejection. 
Weatherley and

Tansik (1993) ${ }^{\mathrm{a}}$

Yi and

Baumgartner

$(2004)^{b}$
Literature review, field observations, interviews with employees, \& field survey

Literature review, $\&$ questionnairebased studies.
Employee

Tactics to manage work demands in service interactions.

Customer

Coping behaviors

Invest additional effort; negotiate to decrease demands (e.g., explain why demands cannot be met); pre-empt imposition of additional demands (e.g., ingratiate customer; distract customer); escape/avoid (e.g., reinterpret customer requests in ways that reduce demands; pretend not to hear customer).

Planful problem solving, confrontative coping, seeking social support, mental disengagement, behavioral disengagement, positive re-interpretation, self-control, and acceptance.

In addition to behaviors with these service interactions, these authors propose a set of extra-encounter behaviors.

b Behaviors identified in this study related to any "purchase related situation", not just service interactions. 
Running Head: SERVICE ENCOUNTER BEHAVIORS

Table 2

Characteristics of the Low and High Poles of each of the T-R-S Dimensions of Service Interaction Behavior

\begin{tabular}{|c|c|c|}
\hline Dimension & Low & High \\
\hline \multirow[t]{7}{*}{ Task } & Task avoidance & Task engagement \\
\hline & Off-task behaviors & On-task behaviors \\
\hline & Lackadaisical, unprofessional & Business-like, professional \\
\hline & Indifference to resource efficiency & Efficient use of resources \\
\hline & Deviation from roles \& norms & Adherence to roles \& norms \\
\hline & Weak service recovery & Strong service recovery \\
\hline & Double deviation & Problem resolution \\
\hline \multirow[t]{7}{*}{ Relationship } & Indifferent to other & Oriented to other \\
\hline & Insensitive, uncaring & Sensitive, empathic \\
\hline & Cold, tough-minded & Warm, tender-hearted \\
\hline & Asocial, or antisocial & Social and prosocial \\
\hline & Relationship-destroying & Relationship-building \\
\hline & Conflict escalation & Conflict minimization and \\
\hline & & management \\
\hline \multirow[t]{5}{*}{ Self } & Selfless & Self-interested \\
\hline & Self-sacrificing & Self-indulgent \\
\hline & Self-effacing & Self-enhancing \\
\hline & Self-injurious & Self-protective/defensive \\
\hline & Sociocentric, allocentric & Egocentric \\
\hline
\end{tabular}


Table 3

Interviewee Comments Illustrating Each of the Eight T-R-S Segments

T-R-S Segment Comment

1. High Task High Relationship High Self

2. High Task High Relationship Low Self

3. Low Task High Relationship Low Self

4. Low Task High Relationship High Self

5. High Task Low Relationship High Self

6. High Task Low Relationship Low Self

7. Low Task Low Relationship Low Self
8. Low Task Low Relationship High Self

If you are fairly courteous and non-aggressive towards them [customer contact staff], they will try to help you. I do find though at some point I need to be assertive to get what I am after, as I am the customer after all. (Female customer)

Just keep smiling! I tell the girls that all the time. You just have to keep smiling and bite your tongue. No matter what happens, the end result is that the customer is going to win. So you just have to deal with it and move on. (Female call center manager).

If you let the customer sort of air out what they need to air out, listen to them ... most people will eventually calm down and be okay ... But, until they do, and it can take a while, it is frustrating for everyone concerned. (Male administrative officer, university)

I sometimes spend too long on the phone. But I am enjoying the conversation, and they are too ... I don't care. (Female employee, call center operator, local government)

If you don't adhere to company policy, a lot of the time it can come back and hit you in the face, because you do something and everything is audio-recorded, you know? So, it's recorded, so I have to cover myself ... As to whether it's detrimental to them, perhaps it is, but I've always covered myself at the same time. (Female student administration officer, university)

It requires them [service employees] to bury ... to sort of overcome whatever emotional issues they may be feeling on that day ... without feigning or going too far in pleasantries. Still keep it as a business issue, really just keep a general business-like demeanor in the conversation. (Male customer)

Some [employees] just get really frustrated with the customer to the point where they start being difficult themselves and they'll say, "I can't hear you properly", or "I don't know what you're talking about", and things like that. ... I've got one person in particular who just gets frustrated with the customer and keeps the [phone] 'hold' button down. (Female supervisor, local government)

There are little sort of power things. Like, I am at a counter and they [the customer] will go to the other end and want me to walk to them when this counter is already open and the other isn't. And it's, you know, "You come up here", and they're saying, "No, you come down here". And I'm like, "No, this is where I'm serving people". (Female library attendant, university) 


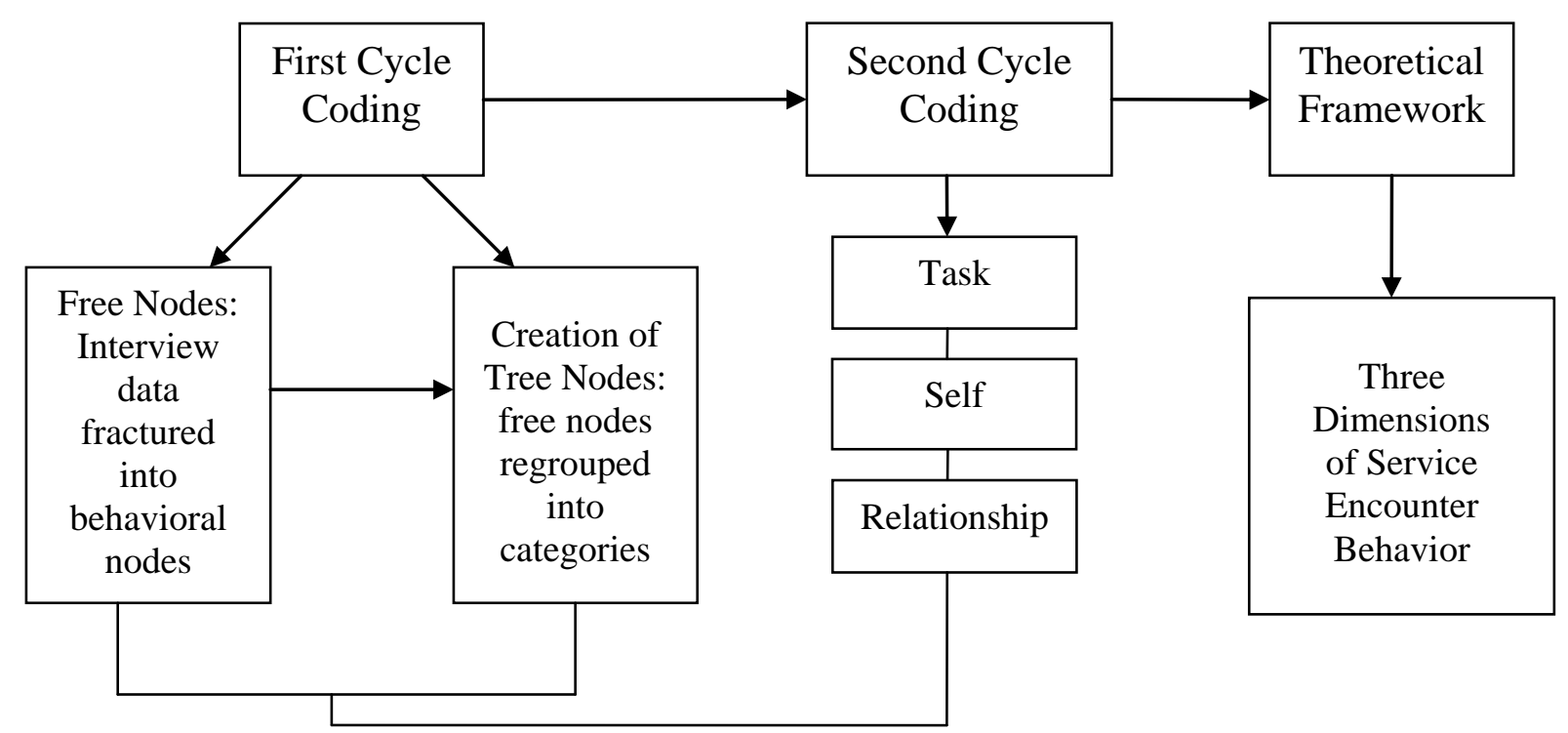

Figure 1. Overview of the analysis and framework derivation process 


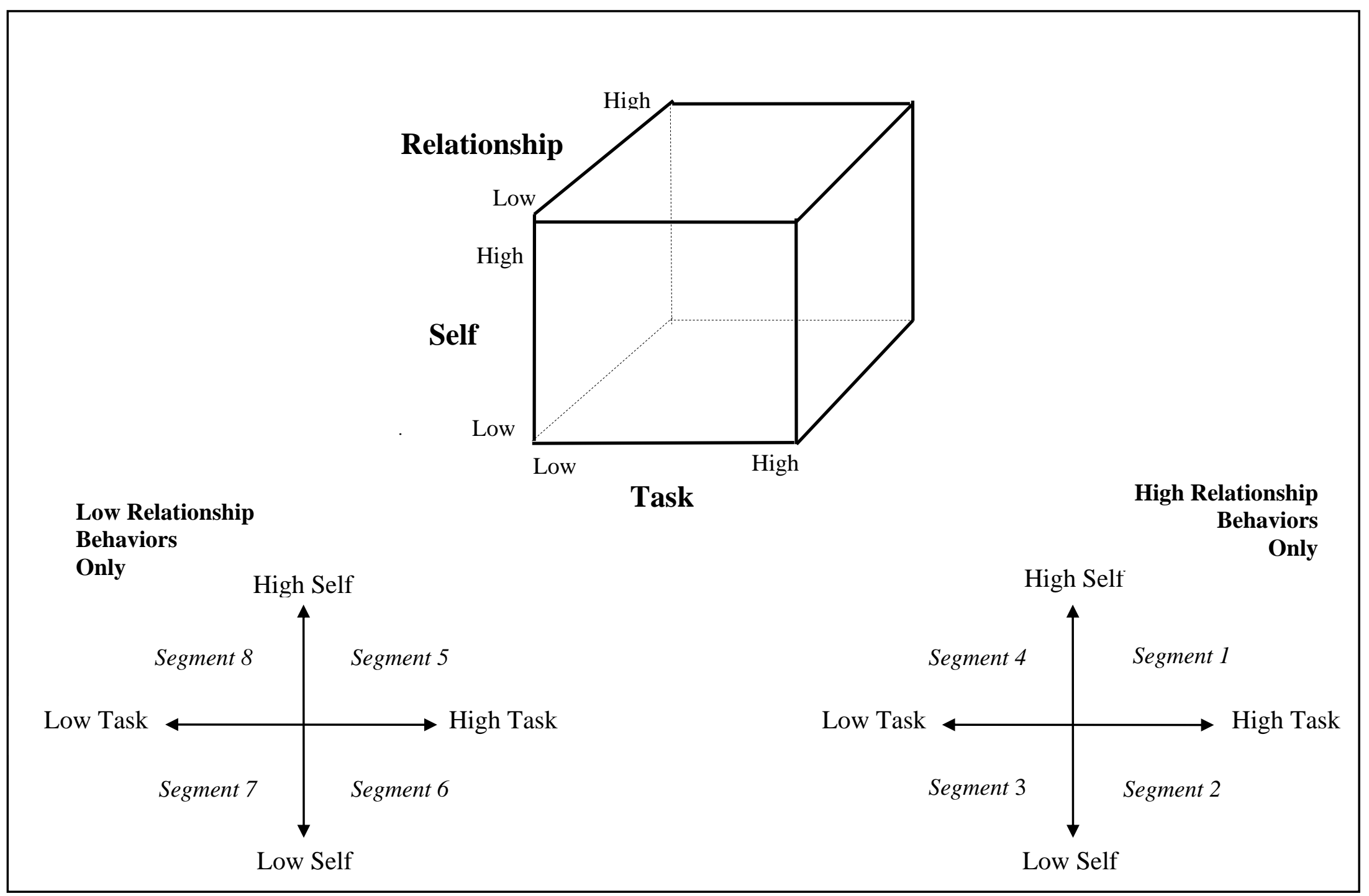

Figure 2. Tier 3 of the Task-Relationship-Self (T-R-S) framework. 
Running Head: SERVICE ENCOUNTER BEHAVIORS

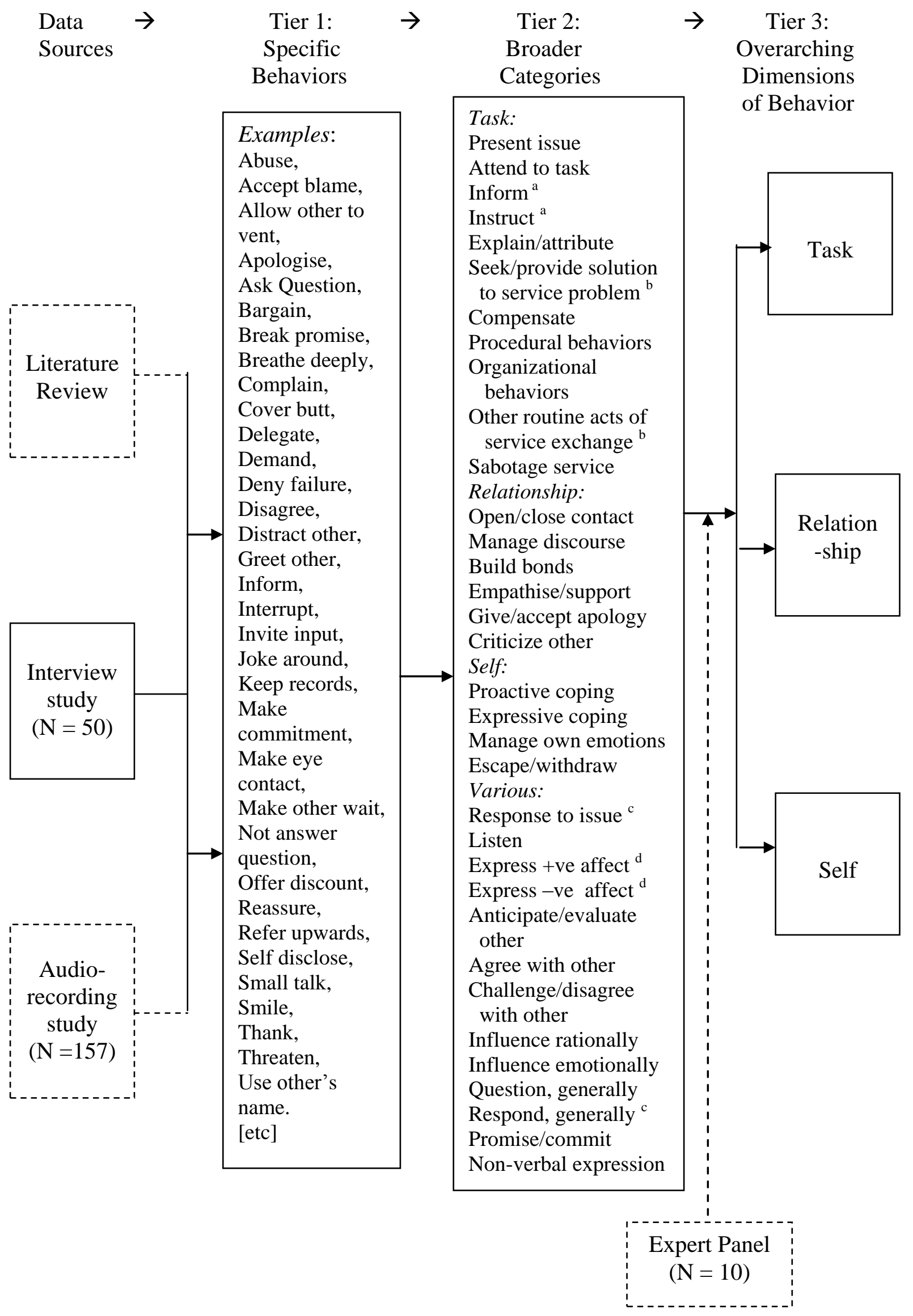

Figure 3. Overview of the T-R-S framework and data sources.

Note. Tier 2 behavioral categories with common superscripts comprised a single parent node in the original 30-category model, but were split into two on the basis of the audio data. 